\title{
An 'activatable' aptamer-based fluorescence probe for the detection of HepG2 cells
}

\author{
ZONGQIANG LAI*, JUNTAO TAN* ${ }^{*}$, RUIRONG WAN* ${ }^{*}$ JIE TAN, ZHENGHUA ZHANG, ZIXI HU, JIEPING LI, \\ WEI YANG, YIWEI WANG, YAFENG JIANG, JIAN HE, NUO YANG, XIAOLING LU and YONGXIANG ZHAO \\ National Center for International Research of Biological Targeting Diagnosis and Therapy, \\ Guangxi Key Laboratory of Biological Targeting Diagnosis and Therapy Research, Collaborative Innovation Center \\ for Targeting Tumor Diagnosis and Therapy, Guangxi Medical University, Nanning, Guangxi 530021, P.R. China
}

Received October 27, 2016; Accepted March 1, 2017

DOI: $10.3892 / o r .2017 .5527$

\begin{abstract}
It is significant to develop a probe with sensitivity and specificity for the detection of cancer cells. The present study aimed to develop an 'activatable' aptamer-based fluorescence probe (AAFP) to detect cancer cells and frozen cancer tissue. This AAFP consisted of two fragments: aptamer TLS11a that targets HepG2 cells, and two short extending complementary DNA sequences with a 5'- and 3'-terminus that make the aptamer in hairpin structure a capable quencher to fluorophore. The ability of the AAFP to bind specifically to cancer cells was assessed using flow cytometry, fluorescence spectroscopy and fluorescence microscopy. Its ability to bind to frozen cancer tissue was assessed using fluorescence microscopy. As a result, in the absence of cancer cells, AAFP showed minimal fluorescence, reflecting auto-quenching. In the presence of cancer cells, however, AAFP showed a strong fluorescent signal. Therefore, this AAFP may be a promising tool for sensitive and specific detection of cancer.
\end{abstract}

\section{Introduction}

The growing incidence of cancer and associated mortality worldwide highlights the importance of timely and effective diagnostic methods (1). Fluorescent probes that specifically recognize molecular targets have proven useful in many areas of biology and medicine, and they show potential for sensitive cancer diagnosis (2-4). Such probes are usually created by

Correspondence to: Professor Yongxiang Zhao or Professor Xiaoling Lu, National Center for International Research of Biological Targeting Diagnosis and Therapy, Guangxi Key Laboratory of Biological Targeting Diagnosis and Therapy Research, Collaborative Innovation Center for Targeting Tumor Diagnosis and Therapy, Guangxi Medical University, Nanning, Guangxi 530021, P.R. China E-mail: yongxiang_zhao@126.com

E-mail: luwuliu@163.com

${ }^{*}$ Contributed equally

Key words: aptamer, activatable, probe, cancer cell, frozen cancer tissue conjugating a reporter fluorophore to an affinity reagent, such as a monoclonal antibody, peptide or aptamer, which binds specifically to the target of interest (5-8). To ensure specificity and sensitivity, the fluorophore must emit a strong signal and be photostable. It may emit minimal fluorescence in the absence of a target, however, in the presence of one the affinity reagent may bind to the target with high specificity and affinity (9). A key challenge in designing fluorescence probes is minimizing background signals in the absence of a target.

Nucleic acid aptamers, which are short, single-stranded RNA or DNA oligonucleotides, show substantial promise as affinity agents (10-13). They have several advantages over other affinity reagents, including high affinity and specificity, facile synthesis and modification and a structure-controlled design. Compared to other affinity reagents, aptamers may be taken up more quickly by tissue, penetrate more deeply into tissue, accumulate more in target tissue and persist less in non-target organs and circulation $(14,15)$. These characteristics make aptamers well suited for cancer detection.

In the present study, we described the development of an activatable aptamer-based fluorescence probe (AAFP) to detect cancer cells and frozen cancer tissue (Fig. 1). This probe was 'activatable' since it was designed to emit minimal signals in the absence of a target, which may lead to decreased background interference than 'always on' fluorescence probes (16). Our AAFP was a short, single-stranded DNA oligonucleotide: we used the DNA aptamer TLS11a, which binds with high affinity to cancer cells (17), and added one short DNA sequence (C-strand) to each end. The two C-strands were complementary to each other, and the $5^{\prime} \mathrm{C}$-strand was conjugated to the fluorophore FAM, while the 3' C-strand was conjugated to the quencher Eclipse. In the absence of a target, the two C-strands hybridized into a hairpin structure, bringing the fluorophore and quencher together and minimizing background fluorescence. Upon target binding, the two C-strands separated, strongly increasing FAM fluorescence signals.

\section{Materials and methods}

Materials. All DNA oligonucleotides were synthesized by Shanghai Sangon Biological Engineering Technology \& Services (Shanghai, China). These oligonucleotides included 
the FAM-labeled TLS11a aptamer (FAM-TLS11a), 5'-FAM-ACAGCATCCCCATGTGAACAATCGCATTGTG ATTGTTACGGTTTCCGCCTCATGGACGTGCTG-3'; the activatable aptamer fluorescence probe with 4 extending C-strand bases (AAFP), 5'-FAM-GGGGACAGCATCCCCAT GTGAACAATCGCATTGTGATTGTTACGGTTTCCGC CTCATGGACGTGCTGCCCC-3'; the AAFP-3 and AAFP-5 mean probes containing 3 and 5 extending $C$-strand bases respectively; a probe with a 5-base mismatch (AAFP-mis), 5'-FAM-GGGGACAGCATCCCCATGTGAATCGAGGCAT TGTGATTGTTACGGTTTCCGCCTCATGGACGTGCTG CCCC-3'. In all the sequences, the extending C-strand bases are underlined and the mismatched bases are bolded and italicized.

Cells and animals. Cell lines were obtained from the National Center for International Research of Biological Targeting Diagnosis and Therapy of Guangxi Medical University. Human hepatocellular carcinoma HepG2, and human normal liver L02 cells were cultured at $37^{\circ} \mathrm{C}$ in Dulbecco's modified Eagle's medium (DMEM) supplemented with $10 \%$ fetal bovine serum (FBS; HyClone, Logan, UT, USA), and 100 U/ml penicillin-streptomycin in a $5 \% \mathrm{CO}_{2}$ atmosphere.

Six-week-old female BALB/c nude mice from the Guangxi Laboratory Animal Center (Guangxi, China) were raised in sterile conditions in a laminar flow hood. All experiments were carried out according to the guidelines of the Federation of European Laboratory Animal Science Associations, and all protocols were approved by the Institutional Animal Care and Use Committee of Guangxi Medical University.

Flow cytometry. Cells were cultured at a density of $5.0 \times 10^{5}$ cells $/ \mathrm{ml}$, collected by centrifugation and resuspended in $0.5 \mathrm{ml}$ of phosphate-buffered saline (PBS). In order to investigate the ability of AAFP to bind to cancer cells, cells were incubated with FAM-TLS11a, AAFP or AAFP-mis $(250 \mathrm{nM})$ at $4^{\circ} \mathrm{C}$ in the dark for $30 \mathrm{~min}$ in $0.5 \mathrm{ml}$ of binding buffer [PBS supplemented with $5 \mathrm{mM} \mathrm{MgCl}, 4.5 \mathrm{~g} / 1$ glucose and $1 \mathrm{mg} / \mathrm{ml}$ bovine serum albumin (BSA)]. Then cells were washed with PBS, suspended in $0.5 \mathrm{ml}$ of binding buffer and analyzed. Fluorescent cells were detected using flow cytometry (Beckman Coulter Epics XL; Beckman Coulter, Inc., Brea, CA, USA), and data were analyzed using FlowJo Software 7.6.2 (FlowJo LLC, Ashland, OR, USA).

Fluorescence spectroscopy. Cells were collected by centrifugation and suspended in $0.5 \mathrm{ml}$ of binding buffer. To assess the increase in AAFP fluorescence upon target binding, cells were incubated with FAM-TLS11a, AAFP or AAFP-mis (250 nM) at $4^{\circ} \mathrm{C}$ in the dark for $30 \mathrm{~min}$. Different lengths of the $\mathrm{C}$-strand on AAFP were tested, as were different AAFP concentrations, incubation times and incubation temperatures. After incubation, binding reactions were analyzed by fluorescence spectroscopy (Hitachi, F-7000; Hitachi, Tokyo, Japan) at the wavelength range of $650-500 \mathrm{~nm}$ with an excitation wavelength at $490 \mathrm{~nm}$. Fluorescence spectra were also obtained from cell suspensions or AAFP on their own in binding buffer as negative controls.

To investigate the sensitivity of AAFP binding to HepG2 cells, serial dilutions of cells $\left(0-1.0 \times 10^{6}\right)$ in $0.5 \mathrm{ml}$ of binding buffer were incubated with AAFP $(250 \mathrm{nM})$ at $4^{\circ} \mathrm{C}$ in the dark for $30 \mathrm{~min}$. Binding reactions were analyzed by fluorescence spectroscopy as described above.

Immunofluorescence imaging of cells. Cells were seeded into 6 -well plates and cultured for $24 \mathrm{~h}$. Cells were fixed with $4 \%$ paraformaldehyde (Sigma-Aldrich, St. Louis, MO, USA) for 20 min, washed with PBS, then incubated with FAM-TLS11a, AAFP or AAFP-mis in binding buffer at $4^{\circ} \mathrm{C}$ in the dark for 30 min. Cells were then washed again with PBS and stained with 4',6-diamidino-2-phenylindole dihydrochloride (DAPI; Life Technologies, Foster City, CA, USA) for $5 \mathrm{~min}$ in the dark. Finally, cells were washed and examined by fluorescence microscopy (Nikon DS-Ri1; Nikon, Tokyo, Japan).

Cancer model and immunofluorescence imaging of frozen cancer sections. BALB/c nude mice received a subcutaneous injection of $5 \times 10^{6} \mathrm{HepG} 2$ cells on their backside. Tumors were allowed to grow for 15-20 days until reaching a diameter of $0.5-1.5 \mathrm{~cm}$. Mice were sacrificed, the cancer tissue was excised, and frozen sections 6-8-mm of thickness were prepared immediately. As a control, normal liver tissue was obtained from the mice that did not receive HepG2 injections.

Frozen sections were fixed with $4 \%$ paraformaldehyde (Sigma-Aldrich) for $10 \mathrm{~min}$, washed with PBS, stained with DAPI for $5 \mathrm{~min}$, washed again, and were then incubated with FAM-TLS11a, AAFP or AAFP-mis $(250 \mathrm{nM})$ at $4^{\circ} \mathrm{C}$ in the dark for $30 \mathrm{~min}$. Finally, the sections were washed again with PBS and observed using fluorescence microscopy.

Statistical analyses. Each experiment was carried out in triplicate. Data are expressed as the mean \pm SD or as the median (range). All statistical analyses were performed using GraphPad Prism 6.02 (GraphPad Software, San Diego, CA, USA). The threshold of significance in all analyses was $\mathrm{P}<0.05$.

\section{Results}

Activation of AAFP fluorescence by target cancer cells. Flow cytometry was used to investigate the ability of target cancer cells to activate AAFP fluorescence. Both FAM-TLS11a and AAFP bound to HepG2 cells, but not to L02 cells, while AAFP-mis did not bind to either cell line (Fig. 2A and B). FAM-TLS11a and AAFP showed similar rates of binding to HepG2 cells, which were significantly higher than the rate of AAFP-mis binding.

Fluorescence spectroscopy was used to analyze the increase in FAM signals due to AAFP binding to HepG2 cells (Fig. 2C and D). Negligible fluorescence was detected in the cell suspensions without the probe or in a solution of AAFP (250 nM) without cells. Incubating HepG2 cells with AAFP led to a strong fluorescence signal at $518 \mathrm{~nm}$, which was much weaker when L02 cells were incubated with AAFP. These results indicate that AAFP fluorescence increased specifically in response to HepG2 cancer cells.

Optimization of $C$-strand length on AAFP. We tested various lengths of the C-strand on AAFP, from 3 to 5 bases, in an effort to minimize background fluorescence while maintaining strong affinity for HepG2 cells. The highest signal-to-background ratio was obtained when the two C-strands contained 


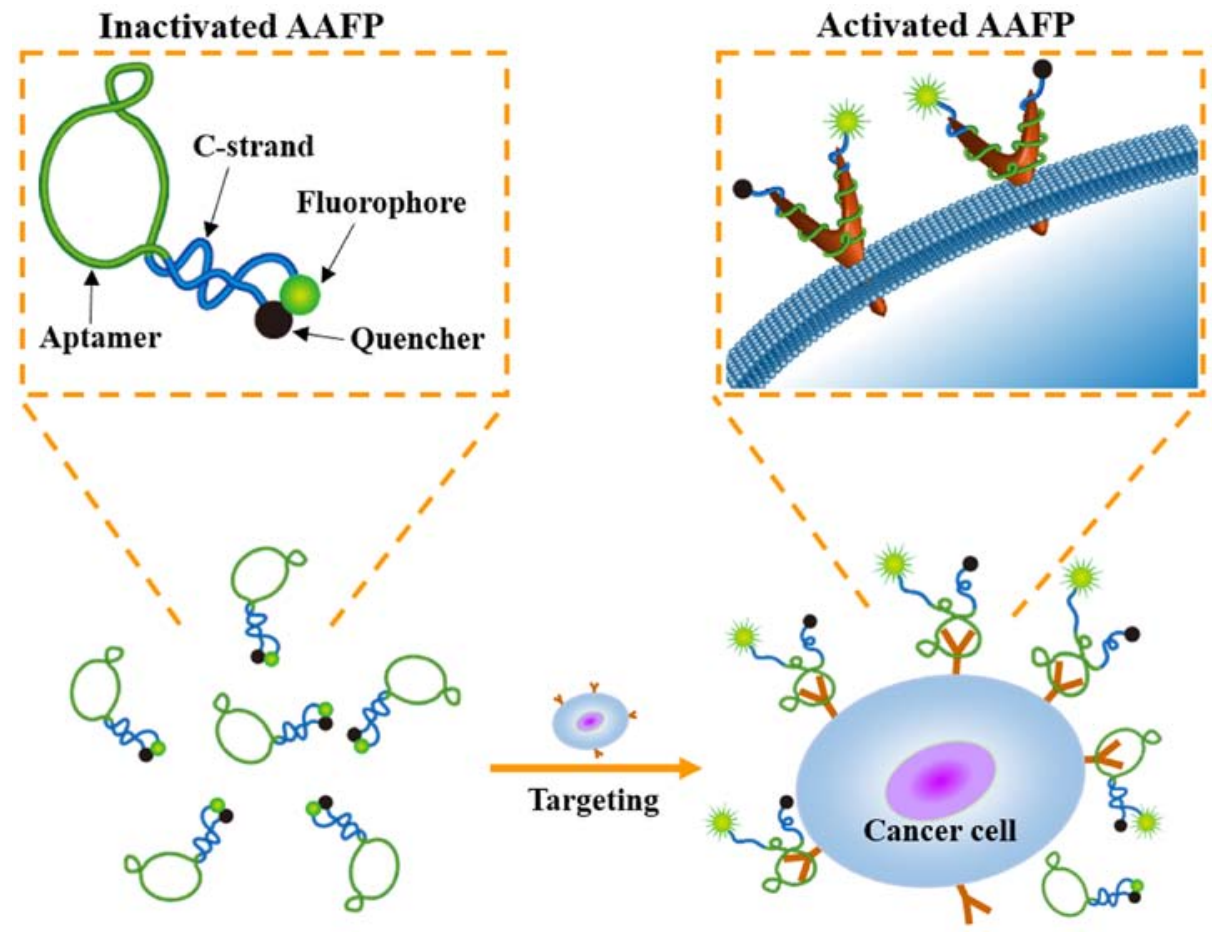

Figure 1. Schematic illustration of cancer cell detection by AAFP.

A

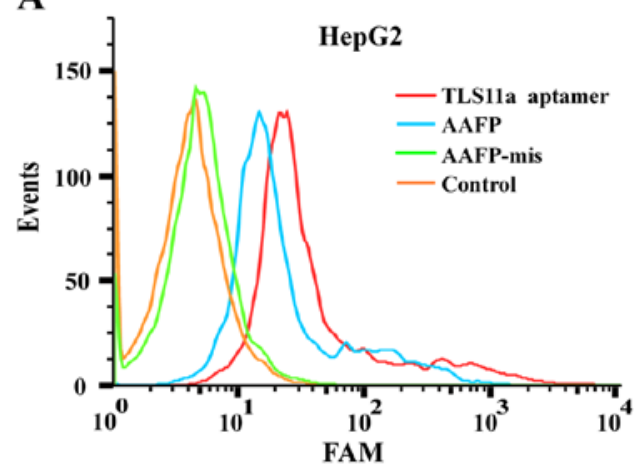

C

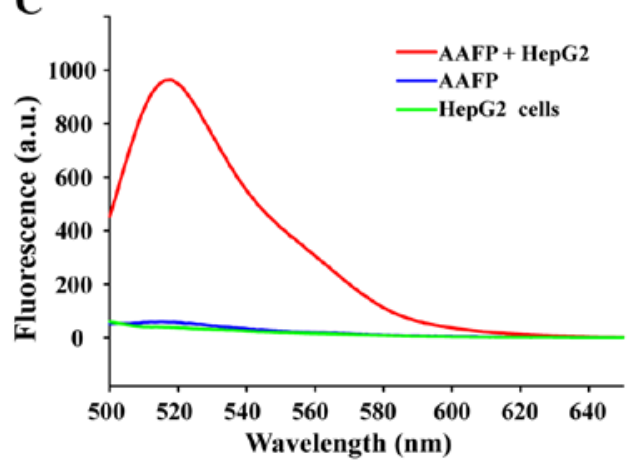

B

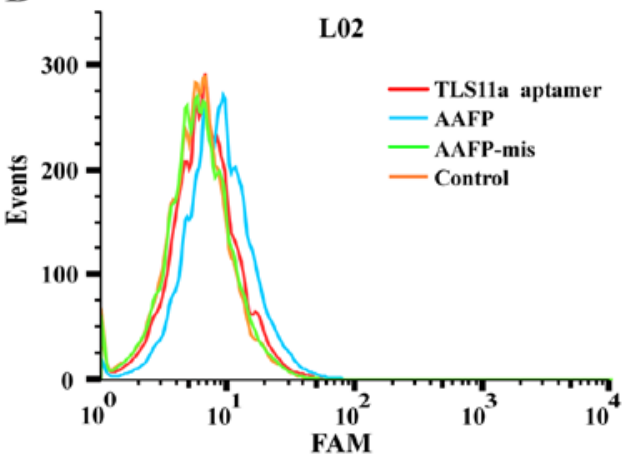

D

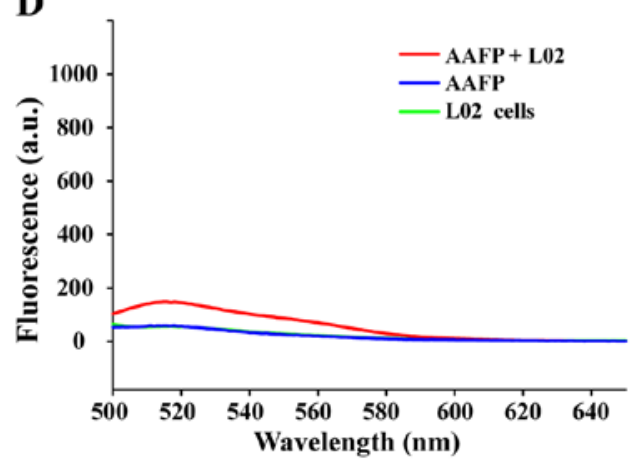

Figure 2. Analysis of target binding by AAFP using flow cytometry and fluorescence spectroscopy. (A and B) TLS11a aptamer, AAFP or AAFP-mis were incubated with (A) HepG2 or (B) L02 cells, which were then analyzed by flow cytometry. (C and D) Fluorescence spectra were recorded for AAFP (250 nM) on its own in PBS, cells on their own $\left(\sim 5 \times 10^{5}\right.$ cells/ml) or mixtures of AAFP and cells incubated. Experiments with (C) HepG2 and (D) L02 cells.

4 bases, corresponding to 4 base pairs in the hairpin structure that forms in the absence of a target (Fig. 3A). This ratio gradually decreased as the number of bases was increased above 4 . We speculated that $\mathrm{C}$-strands with fewer than 4 bases are incapable of keeping the fluorophore and quencher close together, whereas C-strands longer than 4 bases decrease the affinity of the aptamer for target cells.

Optimization of the detection conditions. We investigated the optimal conditions for AAFP binding to HepG2 cells. Cells 
A

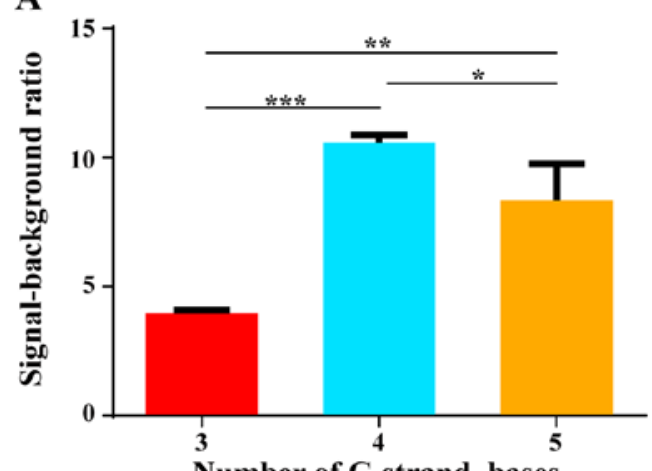

C

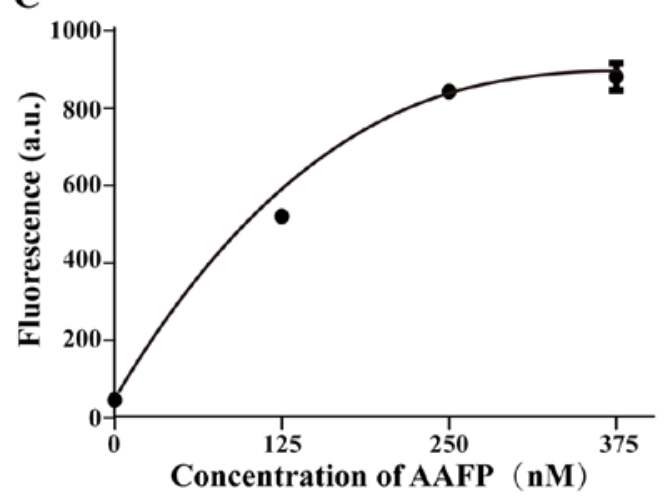

B

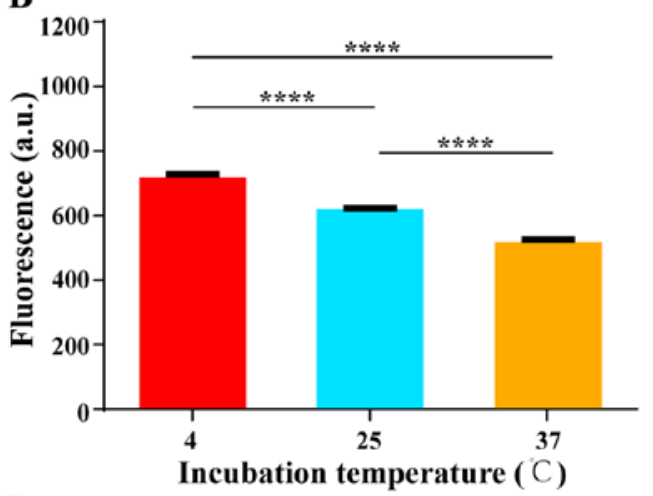

D

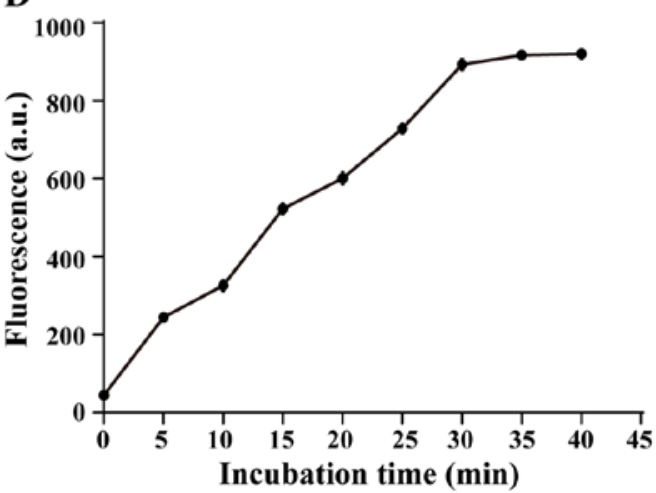

Figure 3. Optimization of C-strand length and detection conditions. (A) Dependence of signal-to-background ratio on the number of bases on the C-strands. (B) Fluorescence intensity of AAFP at $250 \mathrm{nM}$ after 30 min of incubation with HepG2 cells at 4,25 and $37^{\circ} \mathrm{C}$. (C) Fluorescence intensity of AAFP at different concentrations after $30 \mathrm{~min}$ of incubation with $\mathrm{HepG} 2$ cells at $4^{\circ} \mathrm{C}$. (D) Fluorescence intensity of AAFP at $250 \mathrm{nM}$ after incubation with HepG2 cells at $4^{\circ} \mathrm{C}$ for different lengths of time. Data are expressed as the mean $\pm \mathrm{SD}$ of 3 independent experiments; ${ }^{*} \mathrm{P}<0.05,{ }^{* * *} \mathrm{P}<0.01,{ }^{* * * *} \mathrm{P}<0.001,{ }^{* * * * *} \mathrm{P}<0.0001$.

A

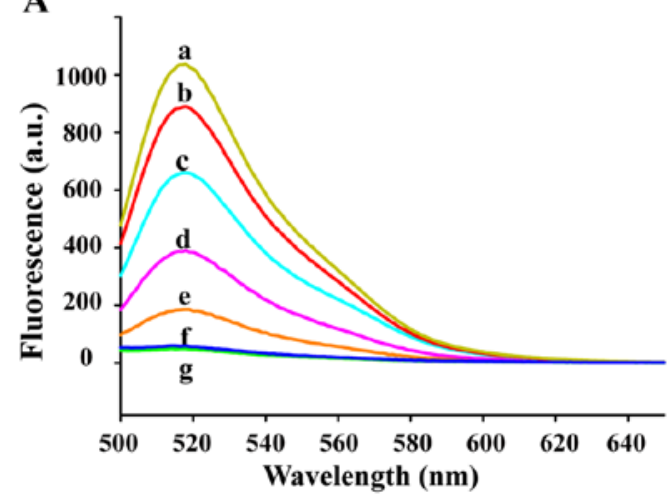

B

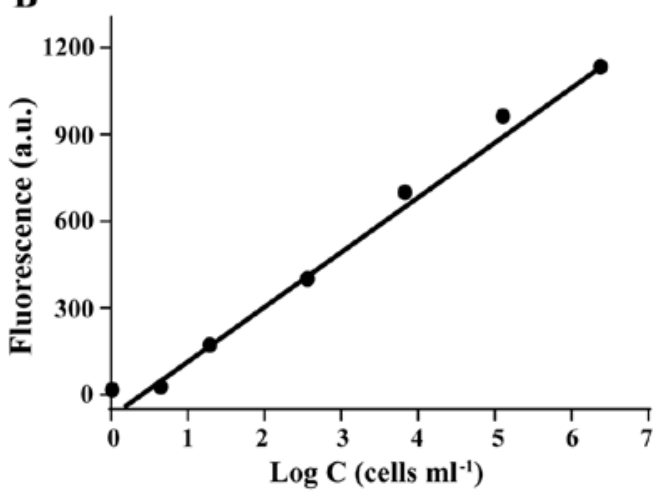

Figure 4. (A) Fluorescence spectra of AAFP after $30 \mathrm{~min}$ of incubation with different concentrations of HepG2 cells (cells/ml): a, $\sim 1 \times 10^{6}$; b, 1x10 5 ; c, 1x10 d, $1 \times 10^{3}$; e, 1x10²; f, 5; g, 0 (green line). (B) Fluorescence signal as a function of the logarithm of HepG2 cell concentration (C).

were incubated with AAFP at $250 \mathrm{nM}$ in the dark for $30 \mathrm{~min}$ at 4,25 or $37^{\circ} \mathrm{C}$, and then activation of AAFP fluorescence was assessed using fluorescence spectroscopy (Fig. 3B). As the temperature increased, fluorescence activation decreased, although it remained well above the background at all temperatures tested. These results indicate that although higher temperatures, including physiological temperatures, slightly decrease the binding of AAFP to target tissues in vitro, the fluorescence signal remains strong relative to the background.

Next, we incubated HepG2 cells with varying AAFP concentrations up to $375 \mathrm{nM}$ at $4^{\circ} \mathrm{C}$ for $30 \mathrm{~min}$, and examined the fluorescence signal (Fig. 3C). The signal increased progressively up to an AAFP concentration of $250 \mathrm{nM}$, after which it almost plateaued, suggesting saturation.

Finally, we incubated HepG2 cells with AAFP at $250 \mathrm{nM}$ for different lengths of time at $4^{\circ} \mathrm{C}$ (Fig. 3D). The fluorescence signal increased gradually from 0 to $30 \mathrm{~min}$, after which it plateaued, suggesting complete binding.

Cancer cell detection by AAFP. To assess the sensitivity of AAFP in the detection of HepG2 cells, we incubated the probe $(250 \mathrm{nM})$ with HepG 2 cells at concentrations of up to $10^{6}$ cell $/ \mathrm{ml}$ in $0.5 \mathrm{ml}$ of binding buffer, and then assessed the fluorescence signal spectroscopically. The signal increased over the entire 
A

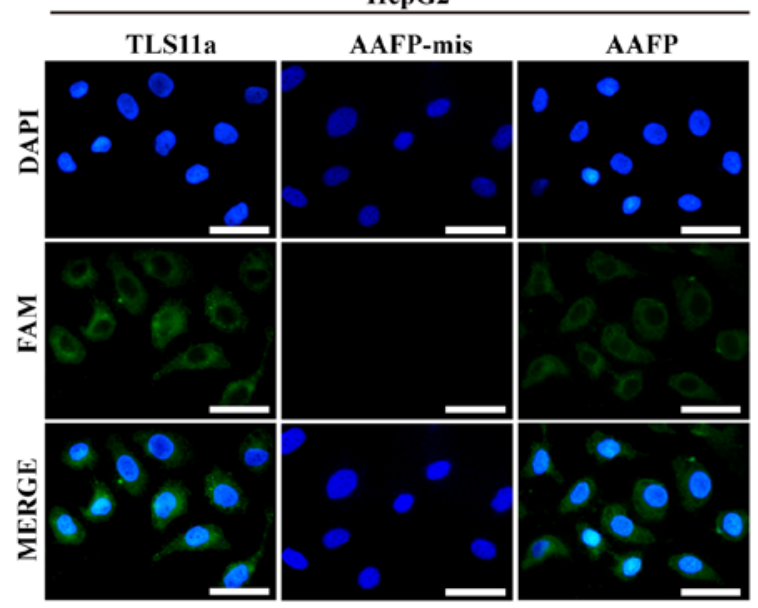

B

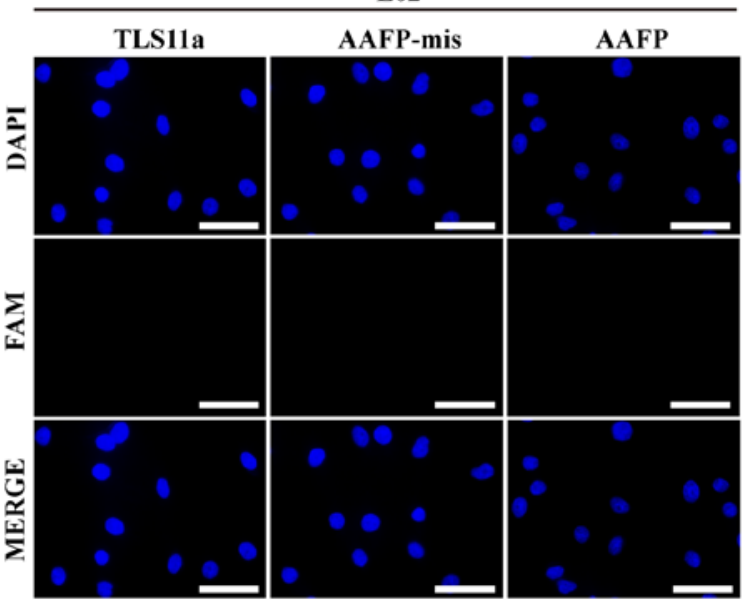

Figure 5. Fluorescence micrographs of (A) HepG2 and (B) L02 cells incubated with TLS11a, AAFP-mis or FAM-AAFP. TLS11a, AAFP-mis and AAFP were examined in the green channel; DAPI-stained nuclei, in the blue channel. Scale bar, $50 \mu \mathrm{m}$.

A

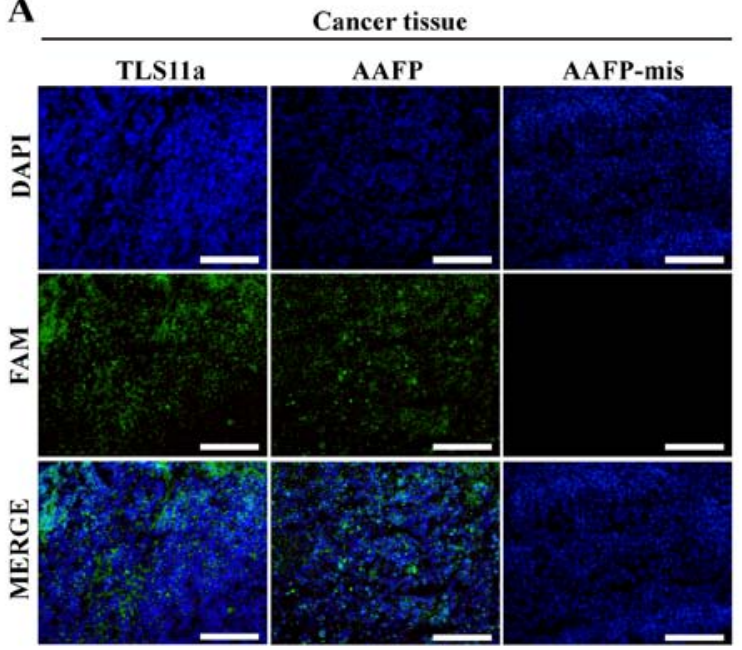

B

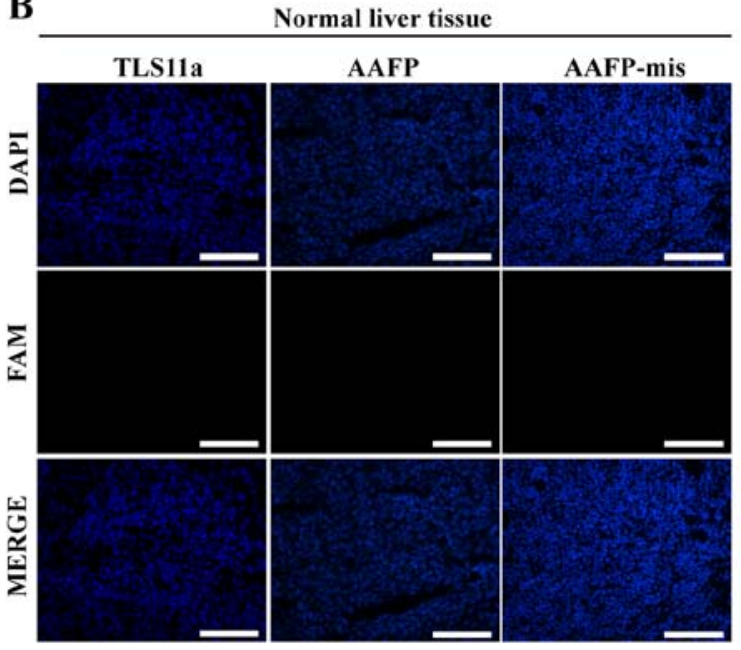

Figure 6. Fluorescence micrographs of frozen sections of (A) cancerous or (B) normal liver tissues after incubation with FAM-TLS11a, AAFP or AAFP-mis. TLS11a, AAFP-mis and AAFP were examined in the green channel; DAPI-stained nuclei, in the blue channel. Scale bar, $100 \mu \mathrm{m}$.

range of cell concentrations assessed (Fig. 4). Regression analysis of the plot of the signal intensity and logarithm of the cell concentration (fluorescence $=214.4 \times \log \mathrm{C}-6.981$ ) revealed that under these experimental conditions, the probe was capable of detecting cancer cells at concentrations as low as $\sim 100$ cells $/ \mathrm{ml}$.

Using AAFP for fluorescence imaging of cancer cells. To visualize directly the specificity of AAFP binding at the cellular level, and thereby complement the flow cytometry experiments as described in Materials and methods, we incubated HepG2 and L02 cells with FAM-TLS11a, AAFP or AAFP-mis and analyzed them using fluorescence microscopy. Consistent with the flow cytometry experiments, AAFP and FAM-TLS11a were observed to bind to HepG2 cells, but not to L02 cells, while AAFP-mis did not bind to either cell type (Fig. 5).

Using AAFP for fluorescence imaging of frozen cancer tissue. We examined whether the specific AAFP binding observed with HepG2 cells in suspension may also apply to frozen sections of solid HepG2 tumors from a xenograft mouse model. As a control, we also examined AAFP binding to frozen sections of normal liver tissue from the same type of mice. Both AAFP and FAM-TLS11a were observed to bind to sections of cancerous tissue, but not to sections of normal tissue (Fig. 6). AAFP-mis did not bind to either type of tissue.

\section{Discussion}

We designed an 'activatable' aptamer-based fluorescence probe (AAFP) that sensitively and specifically detects cancer cells. The probe emitted negligible fluorescence in the absence of target cancer cells since the fluorophore and quencher, conjugated to $\mathrm{C}$-strands on either side of a cancer-specific TLS11a aptamer, lie close together. Then, in the presence of target cancer cells, the fluorophore and quencher separated, giving rise to a strong FAM signal. This AAFP may be a valuable tool for the early detection of cancer, which can 
facilitate timely initiation of treatment. Using an AAFP avoids the need to conjugate a fluorophore to biological tissue, in contrast to other types of fluorescent probes, such as quantum dots $(18,19)$, carbon nanodots $(20)$ and fluorescent dyes $(21,22)$. Under optimal incubation conditions, our AAFP was able to detect cancer cells at concentrations as low as $\sim 100$ cells $/ \mathrm{ml}$.

The TLS11a aptamer, although originally selected for its binding to mouse hepatoma BNL 1ME A.7R.1 (MEAR) cells, also binds with high affinity to human liver cancer cells. TLS11a is likely to be a membrane protein that can be internalized into cells (23), which may explain this dual binding specificity. We found that TLS11a on its own or as part of our AAFP bound efficiently to HepG2 cells, consistent with a previous study (24). In contrast, neither TLS11a nor AAFP bound to normal human L02 liver cells, confirming the cancer specificity of AAFP binding. Further confirmation came when we found that the mismatch-containing AAFP-mis failed to bind to either HepG2 or L02 cells. These results using flow cytometry and fluorescence spectroscopy to examine cells in suspension were confirmed using fluorescence microscopy to examine cells in culture.

We further confirmed the specificity of AAFP binding using frozen sections of HepG2 tumor xenografts and normal liver tissue. Frozen sections are often used for histopathological examination, in part since many proteins retain their activity as in fresh tissue sections, and since they are easier and faster to prepare than paraffin-embedded sections (25).

'Activatable' probes can be superior to 'always on' probes since they emit much less fluorescence in the absence of a target, thereby increasing the signal-to-background ratio $(26,27)$. Our experiments with fluorescence spectroscopy revealed that AAFP emitted minimal fluorescence in the absence of HepG2 cells, likely reflecting fluorescence resonance energy transfer between the fluorophore and quencher lying close together in the hairpin structure formed upon hybridization of the two C-strands. Then, in the presence of HepG2 cells, AAFP fluorescence strongly increased, indicating separation of the fluorophore and quencher due to aptamer binding to targets within the cancer tissue. The high signal-to-background ratio observed for AAFP, even at physiological temperatures, suggests its potential for highly sensitive cancer cell detection.

Optimization studies showed that AAFP binding efficiency depended on the length of the C-strands, the incubation temperature and incubation time. This suggests that studies of AAFP or similar probes may need to screen these parameters carefully to maximize sensitivity and specificity, and in particular to avoid false-negative results. Our observation of maximal binding efficiency at an AAFP concentration of $250 \mathrm{nM}$ is consistent with a previous study (28). The fact that our AAFP bound noticeably less well at $37^{\circ} \mathrm{C}$ than at $4^{\circ} \mathrm{C}$ reflects the fact that the TLS11a aptamer was selected at low temperatures (17). This suggests that optimization of the TLS11a aptamer sequence may improve target binding at physiological temperatures. It also highlights the need to design AAFP-like probes using affinity sequences selected near in vivo temperatures.

The present study further demonstrated the power of aptamers in the detection and imaging of tumor tissues (29). The small size of aptamers may give them an advantage over antibodies for imaging intracellular targets (30), however, they may be rapidly degraded by nucleases or cleared from tissues. Chemically modifying aptamers can render them nuclease-resistant and increase their stability $(31,32)$. Our results open the door to further investigations of AAFP with different chemical modifications.

In summary, we developed a simple, highly sensitive, specific AAFP for the detection of cancer cells and frozen cancer tissue. Our AAFP not only holds great potential in clinical early diagnosis, which can facilitate timely initiation of treatment, but also suggests the possibility of replacing the TLS11a aptamer with other sequences to target other tissue types in cancer or even other diseases.

\section{Acknowledgements}

The present study was supported, in part, by grants from Programs for Changjiang Scholars and Innovative Research Team in University (no. IRT_15R13), the National Natural Scientific Foundation of China (nos. 81430055 and 81372452), the International Cooperation Project of the Ministry of Science and Technology of China (no. 2015DFA31320), the Project for Innovative Research Team in Guangxi Natural Science Foundation (2015GXNSFFA139001), and the Project of Science and Technology of Guangxi (nos. 14125008-2-12 and 1599005-2-10).

\section{References}

1. Siegel RL, Miller KD and Jemal A: Cancer statistics, 2015. CA Cancer J Clin 65: 5-29, 2015.

2. Li C, Meng Y, Wang S, Qian M, Wang J, Lu W and Huang R: Mesoporous carbon nanospheres featured fluorescent aptasensor for multiple diagnosis of cancer in vitro and in vivo. ACS Nano 9: 12096-12103, 2015.

3. Kobayashi H, Longmire MR, Ogawa M, Choyke PL and Kawamoto S: Multiplexed imaging in cancer diagnosis: Applications and future advances. Lancet Oncol 11: 589-595, 2010.

4. Chen TT, Tian X, Liu CL, Ge J, Chu X and Li Y: Fluorescence activation imaging of cytochrome $c$ released from mitochondria using aptameric nanosensor. J Am Chem Soc 137: 982-989, 2015.

5. Zhang M, Chakraborty SK, Sampath P, Rojas JJ, Hou W, Saurabh S, Thorne SH, Bruchez MP and Waggoner AS: Fluoromodule-based reporter/probes designed for in vivo fluorescence imaging. J Clin Invest 125: 3915-3927, 2015.

6. Hou Y, Zhou J, Gao Z, Sun X, Liu C, Shangguan D, Yang W and Gao M: Protease-activated ratiometric fluorescent probe for $\mathrm{pH}$ mapping of malignant tumors. ACS Nano 9: 3199-3205, 2015.

7. Sonn GA, Behesnilian AS, Jiang ZK, Zettlitz KA, Lepin EJ, Bentolila LA, Knowles SM, Lawrence D, Wu AM and Reiter RE: Fluorescent image-guided surgery with an anti-prostate stem cell antigen (PSCA) diabody enables targeted resection of mouse prostate cancer xenografts in real time. Clin Cancer Res 22: 1403-1412, 2016.

8. Hussain T and Nguyen QT: Molecular imaging for cancer diagnosis and surgery. Adv Drug Deliv Rev 66: 90-100, 2014.

9. Jung YK, Woo MA, Soh HT and Park HG: Aptamer-based cell imaging reagents capable of fluorescence switching. Chem Commun 50: 12329-12332, 2014.

10. Lao YH, Phua KK and Leong KW: Aptamer nanomedicine for cancer therapeutics: Barriers and potential for translation. ACS Nano 9: 2235-2254, 2015.

11. Ellington AD and Szostak JW: In vitro selection of RNA molecules that bind specific ligands. Nature 346: 818-822, 1990.

12. Hu Z, Lai Z, He J, Huang X, Hou X, Zhao Y and Lu X: Research progress on cell-SELEX. Cell Commun 2: 57-66, 2015.

13. Tan W, Donovan MJ and Jiang J: Aptamers from cell-based selection for bioanalytical applications. Chem Rev 113: 2842-2862, 2013. 
14. Wang AZ and Farokhzad OC: Current progress of aptamer-based molecular imaging. J Nucl Med 55: 353-356, 2014.

15. Shi H, He X, Wang K, Wu X, Ye X, Guo Q, Tan W, Qing Z, Yang X and Zhou B: Activatable aptamer probe for contrastenhanced in vivo cancer imaging based on cell membrane protein-triggered conformation alteration. Proc Natl Acad Sci USA 108: 3900-3905, 2011.

16. Meng HM, Liu H, Kuai H, Peng R, Mo L and Zhang XB: Aptamer-integrated DNA nanostructures for biosensing, bioimaging and cancer therapy. Chem Soc Rev 45: 2583-2602, 2016.

17. Shangguan D, Meng L, Cao ZC, Xiao Z, Fang X, Li Y, Cardona D, Witek RP, Liu C and Tan W: Identification of liver cancer-specific aptamers using whole live cells. Anal Chem 80: 721-728, 2008.

18. Zhang C, Ji X, Zhang Y, Zhou G, Ke X, Wang H, Tinnefeld P and $\mathrm{He} \mathrm{Z}$ : One-pot synthesized aptamer-functionalized CdTe: $\mathrm{Zn}^{2+}$ quantum dots for tumor-targeted fluorescence imaging in vitro and in vivo. Anal Chem 85: 5843-5849, 2013.

19. Yu Y, Duan S, He J, Liang W, Su J, Zhu J, Hu N, Zhao Y and Lu X: Highly sensitive detection of leukemia cells based on aptamer and quantum dots. Oncol Rep 36: 886-892, 2016.

20. Lee CH, Rajendran R, Jeong MS, Ko HY, Joo JY, Cho S, Chang YW and Kim S: Bioimaging of targeting cancers using aptamer-conjugated carbon nanodots. Chem Commun 49: 6543-6545, 2013.

21. Shi H, Tang Z, Kim Y, Nie H, Huang YF, He X, Deng K, Wang K and Tan W: In vivo fluorescence imaging of tumors using molecular aptamers generated by cell-SELEX. Chem Asian J 5: 2209-2213, 2010

22. Tan J, Yang N, Hu Z, Su J, Zhong J, Yang Y, Yu Y, Zhu J, Xue D, Huang Y, et al: Aptamer-functionalized fluorescent silica nanoparticles for highly sensitive detection of leukemia cells Nanoscale Res Lett 11: 298, 2016.

23. Meng L, Yang L, Zhao X, Zhang L, Zhu H, Liu C and Tan W: Targeted delivery of chemotherapy agents using a liver cancer-specific aptamer. PLoS One 7: e33434, 2012.
24. Kashefi-Kheyrabadi L, Mehrgardi MA, Wiechec E, Turner AP and Tiwari A: Ultrasensitive detection of human liver hepatocellular carcinoma cells using a label-free aptasensor. Anal Chem 86: 4956-4960, 2014

25. Pu Y, Liu Z, Lu Y, Yuan P, Liu J, Yu B, Wang G, Yang CJ, Liu H and Tan W: Using DNA aptamer probe for immunostaining of cancer frozen tissues. Anal Chem 87: 1919-1924, 2015.

26. Yang Y, Huang J, Yang X, Quan K, Xie N, Ou M, Tang J and Wang K: Aptamer-based FRET nanoflares for imaging potassium ions in living cells. Chem Commun 52: 11386-11389, 2016.

27. Zhang L, Cui P, Zhang B and Gao F: Aptamer-based turn-on detection of thrombin in biological fluids based on efficient phosphorescence energy transfer from Mn-doped $\mathrm{ZnS}$ quantum dots to carbon nanodots. Chemistry 19: 9242-9250, 2013.

28. Wu X, Zhao Z, Bai H, Fu T, Yang C, Hu X, Liu Q, Champanhac C, Teng IT, Ye M, et al: DNA aptamer selected against pancreatic ductal adenocarcinoma for in vivo imaging and clinical tissue recognition. Theranostics 5: 985-994, 2015.

29. Wu X, Chen J, Wu M and Zhao JX: Aptamers: Active targeting ligands for cancer diagnosis and therapy. Theranostics 5: 322-344, 2015.

30. Park JY, Lee TS, Song IH, Cho YL, Chae JR, Yun M, Kang H, Lee JH, Lim JH, Cho WG, et al: Hybridization-based aptamer labeling using complementary oligonucleotide platform for PET and optical imaging. Biomaterials 100: 143-151, 2016.

31. Shangguan D, Tang Z, Mallikaratchy P, Xiao Z and Tan W: Optimization and modifications of aptamers selected from live cancer cell lines. ChemBioChem 8: 603-606, 2007.

32. Shigdar S, Macdonald J, O'Connor M, Wang T, Xiang D, Al Shamaileh H, Qiao L, Wei M, Zhou SF, Zhu Y, et al: Aptamers as theranostic agents: Modifications, serum stability and functionalisation. Sensors 13: 13624-13637, 2013. 